Article

\title{
Association between Rheumatoid Arthritis and Meniere's Disease: A Longitudinal Follow-Up Study Using a National Health Screening Cohort
}

\author{
So Young Kim ${ }^{1} \oplus$, Dae Myoung Yoo ${ }^{2}$, Ji Hee Kim ${ }^{3} \oplus$, Mi Jung Kwon ${ }^{4}$, Joo-Hee Kim ${ }^{5}$ and Hyo Geun Choi ${ }^{2,6, *(1)}$ \\ 1 Department of Otorhinolaryngology-Head \& Neck Surgery, CHA Bundang Medical Center, CHA University, \\ Seongnam 13496, Korea; sossi81@hanmail.net \\ 2 Hallym Data Science Laboratory, Hallym University College of Medicine, Anyang 14068, Korea; \\ ydm1285@naver.com \\ 3 Department of Neurosurgery, Hallym University College of Medicine, Anyang 14068, Korea; \\ kimjihee.ns@gmail.com \\ 4 Department of Pathology, Hallym University College of Medicine, Anyang 14068, Korea; \\ mulank@hanmail.net \\ 5 Division of Pulmonary, Allergy, and Critical Care Medicine, Department of Medicine, \\ Hallym University College of Medicine, Anyang 14068, Korea; luxjhee@gmail.com \\ 6 Department of Otorhinolaryngology-Head \& Neck Surgery, Hallym University College of Medicine, \\ Anyang 14068, Korea \\ * Correspondence: pupen@naver.com
}

check for updates

Citation: Kim, S.Y.; Yoo, D.M.; Kim, J.H.; Kwon, M.J.; Kim, J.-H.; Choi, H.G. Association between

Rheumatoid Arthritis and Meniere's Disease: A Longitudinal Follow-Up Study Using a National Health Screening Cohort. J. Clin. Med. 2021, 10, 5694. https://doi.org/10.3390/ jcm10235694

Academic Editor: Chang-Hee Suh

Received: 3 November 2021

Accepted: 2 December 2021

Published: 3 December 2021

Publisher's Note: MDPI stays neutral with regard to jurisdictional claims in published maps and institutional affiliations.

Copyright: (c) 2021 by the authors. Licensee MDPI, Basel, Switzerland. This article is an open access article distributed under the terms and conditions of the Creative Commons Attribution (CC BY) license (https:/ / creativecommons.org/licenses/by/ $4.0 /)$.

\begin{abstract}
This study aimed to evaluate the impact of pre-existing rheumatoid arthritis (RA) on the occurrence of Meniere's disease (MD). The 2002-2015 Korean National Health Insurance ServiceHealth Screening Cohort data were retrospectively analyzed. A total of 3038 participants with RA were matched with 12,152 control participants for demographic factors. The occurrence of MD was evaluated in both the RA and control groups. The hazard ratios (HRs) of RA for participants with MD were calculated using a stratified Cox proportional hazard model. Additionally, subgroup analyses were conducted. The rate of MD was not different between the RA and control groups (1.5\% vs. $1.3 \%$, standardized difference $=0.01$ ). The HR was not higher in the RA group than in the MD group (adjusted $\mathrm{HR}=1.03,95 \%$ confidence interval $=0.73-1.44, p=0.885$ ). A higher HR of RA for participants with MD was found in the $\geq 60$-year-old subgroup in the crude model but not in the adjusted model. An association between RA and MD was not found in any of the other subgroups. A previous history of RA was not related to an increased risk of MD.
\end{abstract}

Keywords: Meniere's disease; rheumatoid arthritis; case-control studies; cohort studies

\section{Introduction}

Rheumatoid arthritis (RA) is a systemic inflammatory disease that primarily involves the joints [1]. Although the prevalence of RA varies according to ethnicity, it is estimated to affect approximately $0.5-2 \%$ of the general population [2]. The pathophysiology of RA is multifactorial and includes genetic, autoimmune, and environmental factors $[3,4]$. Inflammation of the synovial space induces proinflammatory cytokines such as tumor necrosis factor and interleukin-6, which proliferate in synovial cells or pannus and derange cartilage and bony structures [3]. According to the progression of RA, an increasing number of joints are affected by inflammatory changes and develop symptoms of pain and stiffness [4]. In addition to multijoint involvement, RA has been acknowledged to cause extra-articular manifestations, such as rheumatoid nodules and pulmonary, cardiac, and ocular manifestations [5]. Furthermore, the increased risk of falls and vertigo in patients with RA has been attributed to multijoint damage and systemic manifestations [6]. As many as $52.2 \%$ of patients with RA reported falls, and vertigo was associated with a higher risk of recurrent falls (odds ratio $=3.42, p=0.036$ ) [6]. 
Meniere's disease (MD) is a cochleovestibular disorder diagnosed based on the relapsing symptoms of hearing loss, ear fullness, tinnitus, and vertigo [7]. The prevalence of MD was estimated to be approximately 17.0-70.4 cases per 100,000 people [8,9]. The pathophysiology of MD has been explained by several mechanisms, including autoimmunity, inflammation, environmental factors, and genetic factors [10-12]. In particular, the contribution of autoimmunity has been suggested, and MD is considered an autoimmune inner ear disease [13,14]. Compared to a control group, patients with MD showed elevated levels of serum circulating immune complexes (absolute level of optical density at $450 \mathrm{~nm} * 10^{3} / \mathrm{mL}=1445 \pm 577$ vs. $470 \pm 149, p<0.001$ ) [14]. In addition, a randomized controlled trial demonstrated significant improvement in Dizziness Handicap Inventory scores (60.4 vs. 41.3) following intratympanic steroid treatment in patients with MD [15]. Because both MD and RA share a common pathophysiology of autoimmunity, the association of autoimmune arthritis, including RA, with MD has been proposed [13]. However, the prevalence of autoimmune arthritis in patients with MD varies from $1.0 \%$ to $10.0 \%$, and the study population was not standardized to a control population [13].

We hypothesized that a prior history of RA could impact the subsequent occurrence of MD. However, comorbid conditions could influence the association of RA with MD. In addition, the vertigo symptoms in patients with RA could originate from other vestibular disorders. To test this hypothesis, patients with RA were compared with a control group for the new onset of MD. To minimize the potential confounding effects, data on comorbidities, including other vestibular disorders, were collected, and comorbidities were adjusted as covariables.

\section{Materials and Methods}

\subsection{Ethics}

The ethics committee of Hallym University (23 October 2019) approved this study. The requirement for written informed consent was waived by the Institutional Review Board. All analyses adhered to the guidelines and regulations of the ethics committee of Hallym University.

\subsection{Study Population and Participant Selection}

A detailed description of the Korean National Health Insurance Service-Health Screening Cohort data is described elsewhere [16]. This study retrospectively analyzed this cohort data.

RA participants were selected from among 514,866 participants with $615,488,428$ medical claim codes from 2002 through $2015(n=4228)$. The control group was included if participants were not defined as having RA from 2002 through $2015(n=510,638)$. To ensure the selection of participants in whom RA was diagnosed first, RA participants diagnosed in 2002 were excluded (washout period, $n=1079$ ). Control participants were excluded if they had M05 or M06 International Classification of Diseases, 10th Revision (ICD-10), diagnostic codes $(n=78,040)$. Participants who were treated for head traumas (ICD-10 codes: S00 to S09, diagnosed by neurologists, neurosurgeons, or emergency medicine doctors) $\geq 2$ times and evaluated by head and neck computed tomography (CT; claim codes: HA401-HA416, HA441-HA443, HA451-HA453, HA461-HA463, or HA471-HA473) were excluded ( $n=74$ for the RA group, $n=11,061$ for the control group). Control participants who were treated for brain tumors (ICD-10 codes: C70 to C72) $\geq 2$ times $(n=726)$ or disorders of the auditory nerve (ICD-10 codes: H933) $\geq 2$ times $(n=125)$ were excluded. Participants who were treated for benign neoplasms of the cranial nerves (ICD-10 codes: D333) $\geq 2$ times ( $n=3$ for the RA group, $n=191$ for the control group) were excluded. RA participants were 1:4 matched with control participants in terms of age, sex, income, and the region of residence. To avoid selection bias for the selection of matched participants, the control participants were selected in a random number order. The index date of control participants was identically set as that of the matched RA participants. In both the RA and control groups, participants who had a history of MD before the index date were 
excluded. In the RA group, 34 participants were excluded. During the matching procedure, 408,343 control participants were excluded. Finally, 3038 RA participants were 1:4 matched with 12,152 control participants (Figure 1)

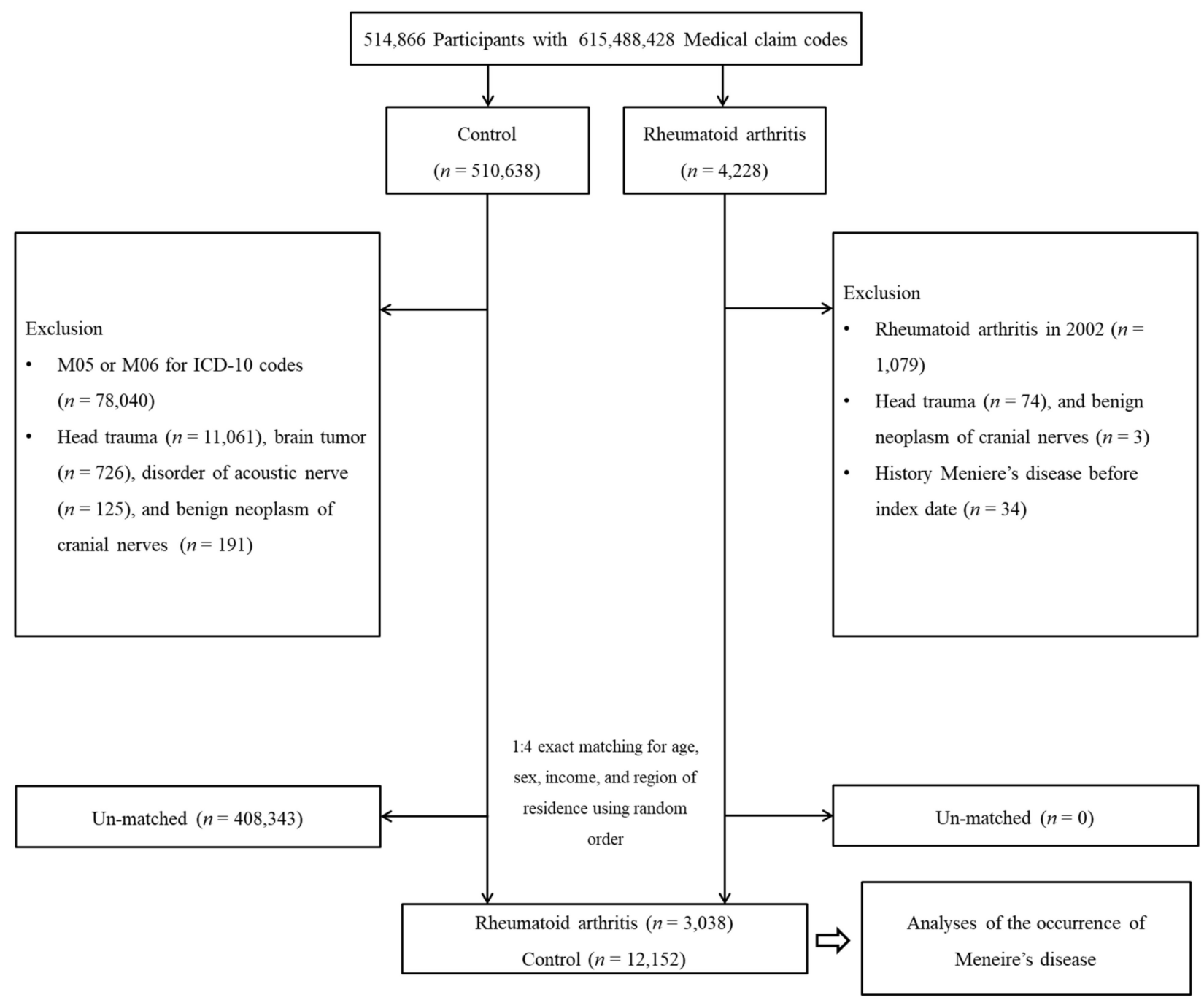

Figure 1. A schematic illustration of the participant selection process that was used in the present study. Among a total of 514,866 participants, 3038 rheumatoid arthritis participants were matched with 12,152 control participants for age, sex, income, and the region of residence.

\subsection{Definition of $R A$}

RA was defined as the presence of ICD-10 codes M05 or M06 and a prescription for a biologic agent or any disease-modifying anti-rheumatic drug (DMARD) [17].

\subsection{Definition of $M D$}

MD was defined as the presence of ICD-10 code H810 (MD). Among participants with this code, we selected those who were treated $\geq 2$ times and underwent an audiometric examination (claim code: E6931-E6937, F6341-F6348) [18].

\subsection{Covariates}

Age groups were divided into 10 groups based on 5-year intervals: 40-44, and $85+$ years. Income was classified into 5 classes (class 1 (lowest income)- 5 (highest income)). The region of residence was classified as urban or rural areas following our previous study [19]. Tobacco smoking, alcohol consumption, obesity (defined using body 
mass index (BMI, $\mathrm{kg} / \mathrm{m}^{2}$ ) based on the Asia-Pacific criteria [20]), systolic blood pressure (SBP, $\mathrm{mmHg}$ ), diastolic blood pressure (DBP, $\mathrm{mmHg}$ ), fasting blood glucose ( $\mathrm{mg} / \mathrm{dL})$, and total cholesterol $(\mathrm{mg} / \mathrm{dL})$ were surveyed or measured. The Charlson Comorbidity Index (CCI) score without rheumatic diseases was calculated. The comorbidities were retrieved based on diagnostic codes (ICD-10).

\subsection{Statistical Analyses}

The standardized difference (SD) was used to compare the rate of general characteristics between the RA and control groups [21]. The SD is an index to measure the effect size between two groups. Because SD is independent of sample size, it can compare baseline covariates in large cohort data.

Stratified Cox proportional hazard models were used to assess the hazard ratios (HRs) and 95\% confidence intervals (CIs) of RA for participants with MD. Crude (simple) and adjusted (obesity, smoking, alcohol consumption, SBP, DBP, fasting blood glucose, total cholesterol, CCI scores, benign paroxysmal vertigo, vestibular neuronitis, and other peripheral vertigo) models were used in these analyses, and the $95 \%$ CI was calculated. In these analyses, age, sex, income, and the region of residence were stratified. A KaplanMeier curve and log rank test were used.

For the subgroup analyses using the stratified Cox proportional hazards model, we divided participants by age ( $<60$ years old and $\geq 60$ years old), sex, income, and the region of residence.

We performed additional subgroup analyses using the unstratified Cox proportional hazards model and analyzed additional subgroup analyses.

Two-tailed analyses were performed, and significance was defined as $p$ values of less than 0.05. SAS version 9.4 (SAS Institute Inc., Cary, NC, USA) was used for statistical analyses.

\section{Results}

A total of $1.5 \%(45 / 3038)$ of RA and $1.3 \%(163 / 12,152)$ of control groups had histories of $\mathrm{MD}(\mathrm{SD}=0.01$, Table 1 ). The RA group and control group had no significant difference in the rates of histories of benign paroxysmal vertigo ( $8.5 \%$ vs. $6.6 \%$, $\mathrm{SD}=0.07)$, vestibular neuronitis $(2.1 \%$ vs. $1.6 \%, \mathrm{SD}=0.04)$, or other peripheral vertigo $(5.1 \%$ vs. $4.5 \%, \mathrm{SD}=0.03)$. The distributions of obesity, smoking status, alcohol consumption, SBP, DBP, fasting blood glucose, total cholesterol, and CCI scores were not significantly different between the RA and control groups.

Table 1. General Characteristics of Participants.

\begin{tabular}{rccc}
\hline Characteristics & \multicolumn{3}{c}{ Total Participants } \\
\hline & $\begin{array}{c}\text { Rheumatoid } \\
\text { Arthritis }(\boldsymbol{n}, \mathbf{\%})\end{array}$ & Control $(\boldsymbol{n}, \mathbf{\%})$ & $\begin{array}{c}\text { Standardized } \\
\text { Difference }\end{array}$ \\
\hline Age (years old) & & & 0.00 \\
$40-44$ & $106(3.5)$ & $424(3.5)$ & \\
$45-49$ & $355(11.7)$ & $1420(11.7)$ & \\
$50-54$ & $658(21.7)$ & $2632(21.7)$ & \\
$55-59$ & $574(18.9)$ & $2296(18.9)$ & \\
$60-64$ & $532(17.5)$ & $2128(17.5)$ & \\
$65-69$ & $417(13.7)$ & $1668(13.7)$ & \\
$70-74$ & $238(7.8)$ & $952(7.8)$ & \\
$75-79$ & $120(4.0)$ & $480(4.0)$ & \\
$80-84$ & $33(1.1)$ & $132(1.1)$ & \\
$85+$ & $5(0.2)$ & $20(0.2)$ & \\
Sex & $815(26.8)$ & $3260(26.8)$ & \\
Male & $2223(73.2)$ & $8892(73.2)$ & \\
Female & &
\end{tabular}


Table 1. Cont.

\begin{tabular}{|c|c|c|c|}
\hline \multirow[t]{2}{*}{ Characteristics } & \multicolumn{3}{|c|}{ Total Participants } \\
\hline & $\begin{array}{l}\text { Rheumatoid } \\
\text { Arthritis }(n, \%)\end{array}$ & Control $(n, \%)$ & $\begin{array}{c}\text { Standardized } \\
\text { Difference }\end{array}$ \\
\hline Income & & & 0.00 \\
\hline 1 (lowest) & $509(16.8)$ & $2036(16.8)$ & \\
\hline 2 & $465(15.3)$ & $1860(15.3)$ & \\
\hline 3 & $514(16.9)$ & $2056(16.9)$ & \\
\hline 4 & $654(21.5)$ & $2616(21.5)$ & \\
\hline 5 (highest) & $896(29.5)$ & $3584(29.5)$ & \\
\hline Region of residence & & & 0.00 \\
\hline Urban & $1311(43.2)$ & $5244(43.2)$ & \\
\hline Rural & $1727(56.9)$ & $6908(56.9)$ & \\
\hline Obesity + & & & 0.05 \\
\hline Underweight & $56(1.8)$ & $276(2.3)$ & \\
\hline Normal & $1156(38.1)$ & 4437 (36.5) & \\
\hline Overweight & $794(26.1)$ & $3269(26.9)$ & \\
\hline Obese I & $942(31.0)$ & $3774(31.1)$ & \\
\hline Obese II & $90(3.0)$ & $396(3.3)$ & \\
\hline Smoking status & & & 0.04 \\
\hline Nonsmoker & $2497(82.2)$ & $10,167(83.7)$ & \\
\hline Past smoker & $208(6.9)$ & $802(6.6)$ & \\
\hline Current smoker & $333(11.0)$ & $1183(9.7)$ & \\
\hline Alcohol consumption & & & 0.04 \\
\hline$<1$ time a week & $2452(80.7)$ & $9616(79.1)$ & \\
\hline$\geq 1$ time a week & $586(19.3)$ & $2536(20.9)$ & \\
\hline Systolic blood pressure & & & 0.07 \\
\hline$<120 \mathrm{mmHg}$ & $986(32.5)$ & $3863(31.8)$ & \\
\hline $120-139 \mathrm{mmHg}$ & $1474(48.5)$ & $5632(46.4)$ & \\
\hline$\geq 140 \mathrm{mmHg}$ & $578(19.0)$ & 2657 (21.9) & \\
\hline Diastolic blood pressure & & & 0.06 \\
\hline$<80 \mathrm{mmHg}$ & $1497(49.3)$ & $5648(46.5)$ & \\
\hline $80-89 \mathrm{mmHg}$ & $1037(34.1)$ & $4265(35.1)$ & \\
\hline$\geq 90 \mathrm{mmHg}$ & $504(16.6)$ & $2239(18.4)$ & \\
\hline Fasting blood glucose & & & 0.08 \\
\hline$<100 \mathrm{mg} / \mathrm{dL}$ & $2125(70.0)$ & $8061(66.3)$ & \\
\hline $100-125 \mathrm{mg} / \mathrm{dL}$ & $710(23.4)$ & $3134(25.8)$ & \\
\hline$\geq 126 \mathrm{mg} / \mathrm{dL}$ & $203(6.7)$ & $957(7.9)$ & \\
\hline Total cholesterol & & & 0.04 \\
\hline$<200 \mathrm{mg} / \mathrm{dL}$ & $1583(52.1)$ & $6128(50.4)$ & \\
\hline 200-239 mg/dL & 1019 (33.5) & $4147(34.1)$ & \\
\hline$\geq 240 \mathrm{mg} / \mathrm{dL}$ & $436(14.4)$ & 1877 (15.5) & \\
\hline CCI score & & & 0.18 \\
\hline 0 & $1989(65.5)$ & 8827 (72.6) & \\
\hline 1 & $556(18.3)$ & $1508(12.4)$ & \\
\hline$\geq 2$ & $493(16.2)$ & $1817(15.0)$ & \\
\hline Benign paroxysmal vertigo & $258(8.5)$ & $796(6.6)$ & 0.07 \\
\hline Vestibular neuronitis & $65(2.1)$ & $190(1.6)$ & 0.04 \\
\hline Other peripheral vertigo & $156(5.1)$ & $550(4.5)$ & 0.03 \\
\hline Meniere's disease & 45 (1.5) & $163(1.3)$ & 0.01 \\
\hline
\end{tabular}

Abbreviations: CCI, Charlson comorbidity index. † Obesity (BMI, body mass index, $\mathrm{kg} / \mathrm{m}^{2}$ ) was categorized as $<18.5$ (underweight), $\geq 18.5$ to $<23$ (normal), $\geq 23$ to $<25$ (overweight), $\geq 25$ to $<30$ (obese I), and $\geq 30$ (obese II).

A history of RA was not associated with MD in either the crude model or the adjusted model (adjusted HR $(\mathrm{aHR})=1.03,95 \% \mathrm{CI}=0.73-1.44, p=0.885$, Table 2). A higher HR of RA for participants with MD was found in the $\geq 60$-year-old subgroup in the crude model $(\mathrm{HR}=1.57,95 \% \mathrm{CI}=1.03-2.40, p=0.035)$ but not in the adjusted model $(\mathrm{aHR}=1.40,95 \%$ $\mathrm{CI}=0.91-2.15, p=0.131)$. 
Table 2. Crude and adjusted hazard ratios of RA for Meniere's disease with subgroup according to age, sex, income, and region.

\begin{tabular}{|c|c|c|c|c|c|c|c|c|}
\hline \multirow{2}{*}{ Independent Variables } & \multirow{2}{*}{$\begin{array}{c}\text { Meniere's } \\
\text { Disease/Participants }(n, \%)\end{array}$} & \multirow{2}{*}{$\begin{array}{c}\text { Follow-Up } \\
\text { Duration (PY) }\end{array}$} & \multirow{2}{*}{$\begin{array}{l}\text { IR Per 10,000 } \\
\text { (PY) }\end{array}$} & \multicolumn{4}{|c|}{$\begin{array}{l}\text { Hazard Ratios for Meniere's Disease } \\
(95 \% \text { Confidence Interval) }\end{array}$} & \multirow{2}{*}{$\begin{array}{c}P \text { for } \\
\text { Interaction }\end{array}$} \\
\hline & & & & Crude + & $p$ Value & Adjusted $† \ddagger$ & $p$ Value & \\
\hline \multicolumn{9}{|c|}{ Total participants $(n=15,190)$} \\
\hline RA & $45 / 3038(1.5)$ & 21,095 & 21.3 & $1.13(0.81-1.57)$ & 0.473 & $1.03(0.73-1.44)$ & 0.885 & \\
\hline Control & $163 / 12,152(1.3)$ & 84,712 & 19.2 & 1 & & 1 & & \\
\hline \multicolumn{2}{|c|}{ Age $<60(n=8465)$} & & & & & & & 0.054 \\
\hline $\mathrm{RA}$ & $15 / 1693(0.9)$ & 13,145 & 11.4 & $0.72(0.42-1.25)$ & 0.243 & $0.68(0.39-1.18)$ & 0.168 & \\
\hline Control & $84 / 6772(1.2)$ & 52,490 & 16.0 & 1 & & 1 & & \\
\hline \multicolumn{9}{|c|}{ Age $\geq 60(n=6725)$} \\
\hline $\mathrm{RA}$ & $30 / 1345(2.2)$ & 7950 & 37.7 & $1.57(1.03-2.40)$ & $0.035 *$ & $1.40(0.91-2.15)$ & 0.131 & \\
\hline Control & $79 / 5380(1.5)$ & 32,222 & 24.5 & 1 & & 1 & & \\
\hline \multicolumn{2}{|c|}{ Men $(n=4075)$} & & & & & & & 0.605 \\
\hline $\mathrm{RA}$ & $5 / 815(0.6)$ & 4991 & 10.0 & $0.87(0.33-2.29)$ & 0.782 & $0.82(0.29-2.29)$ & 0.703 & \\
\hline Control & $25 / 3260(0.8)$ & 20,348 & 12.3 & 1 & & 1 & & \\
\hline \multicolumn{9}{|c|}{ Women $(n=11,115)$} \\
\hline RA & $40 / 2223(1.8)$ & 16,104 & 24.8 & $1.17(0.82-1.67)$ & 0.377 & $1.06(0.74-1.52)$ & 0.737 & \\
\hline Control & 138/8892 (1.6) & 64,364 & 21.4 & 1 & & 1 & & \\
\hline \multicolumn{2}{|c|}{ Low income $(n=7440)$} & & & & & & & 0.279 \\
\hline Control & $75 / 5952(1.3)$ & 42,219 & 17.8 & 1 & & 1 & & \\
\hline \multicolumn{9}{|c|}{ High income $(n=7750)$} \\
\hline RA & $29 / 1550(1.9)$ & 10,567 & 27.4 & $1.34(0.88-2.04)$ & 0.171 & $1.20(0.78-1.84)$ & 0.410 & \\
\hline Control & $88 / 6200(1.4)$ & 42,493 & 20.7 & 1 & & 1 & & \\
\hline \multicolumn{2}{|c|}{ Urban residents $(n=6555)$} & & & & & & & 0.723 \\
\hline RA & $20 / 1311(1.5)$ & 9257 & 21.6 & $1.12(0.68-1.84)$ & 0.647 & $0.99(0.59-1.64)$ & 0.957 & \\
\hline Control & $72 / 5244(1.4)$ & 37,291 & 19.3 & 1 & & 1 & & \\
\hline \multicolumn{9}{|c|}{ Rural residents $(n=8635)$} \\
\hline RA & $25 / 1727(1.4)$ & 11,838 & 21.1 & $1.13(0.73-1.77)$ & 0.580 & $1.09(0.69-1.71)$ & 0.715 & \\
\hline Control & $91 / 6908(1.3)$ & 47,421 & 19.2 & 1 & & 1 & & \\
\hline
\end{tabular}

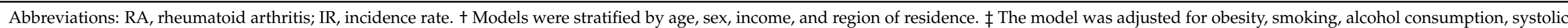

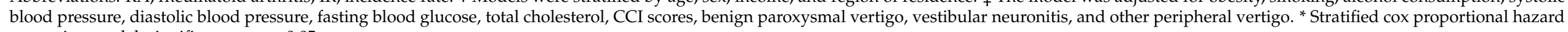
regression model; significance at $p<0.05$. 


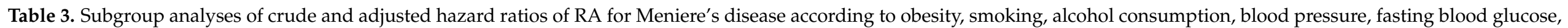
total cholesterol, CCI scores, benign paroxysmal vertigo, vestibular neuronitis, and other peripheral vertigo.

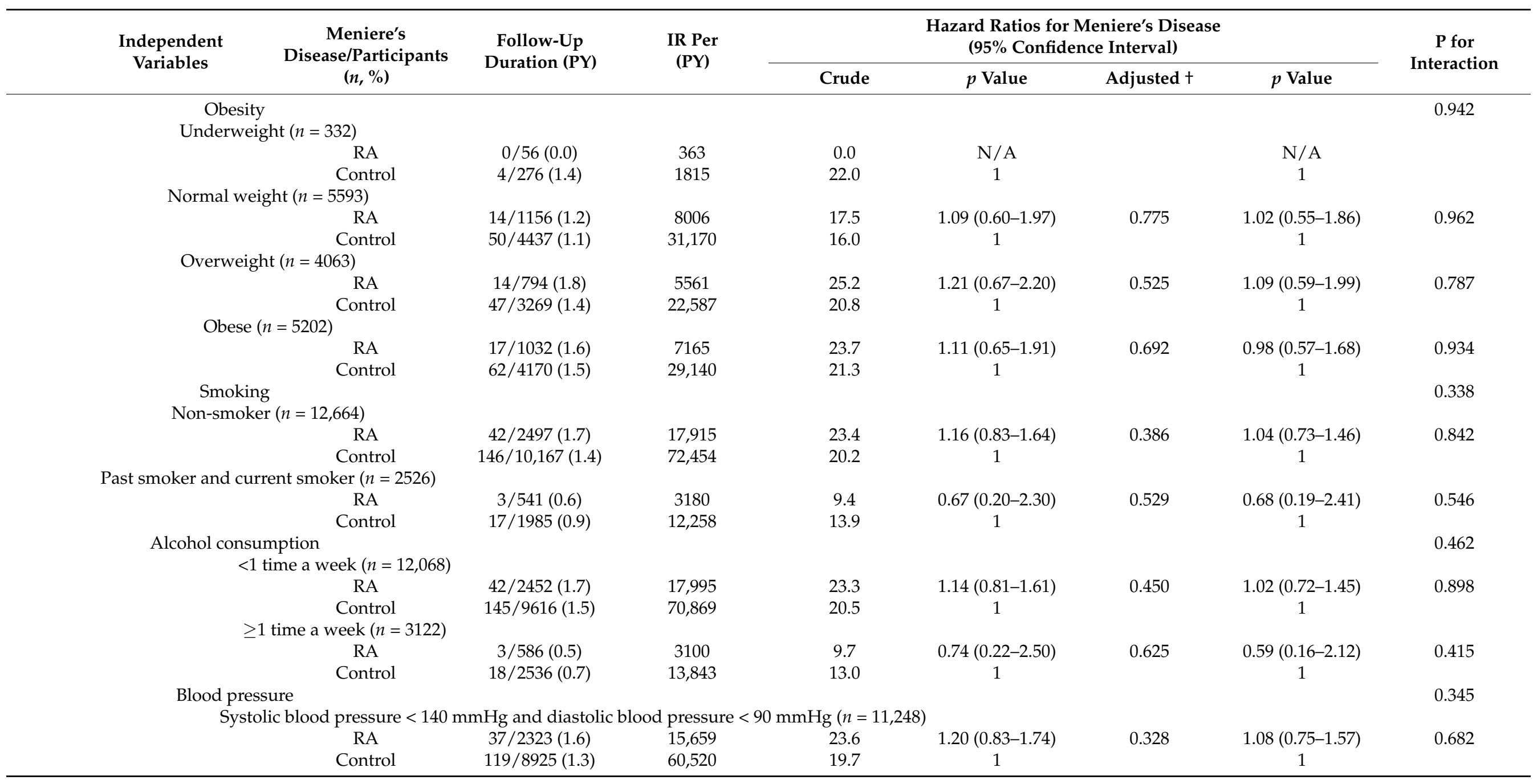


Table 3. Cont.

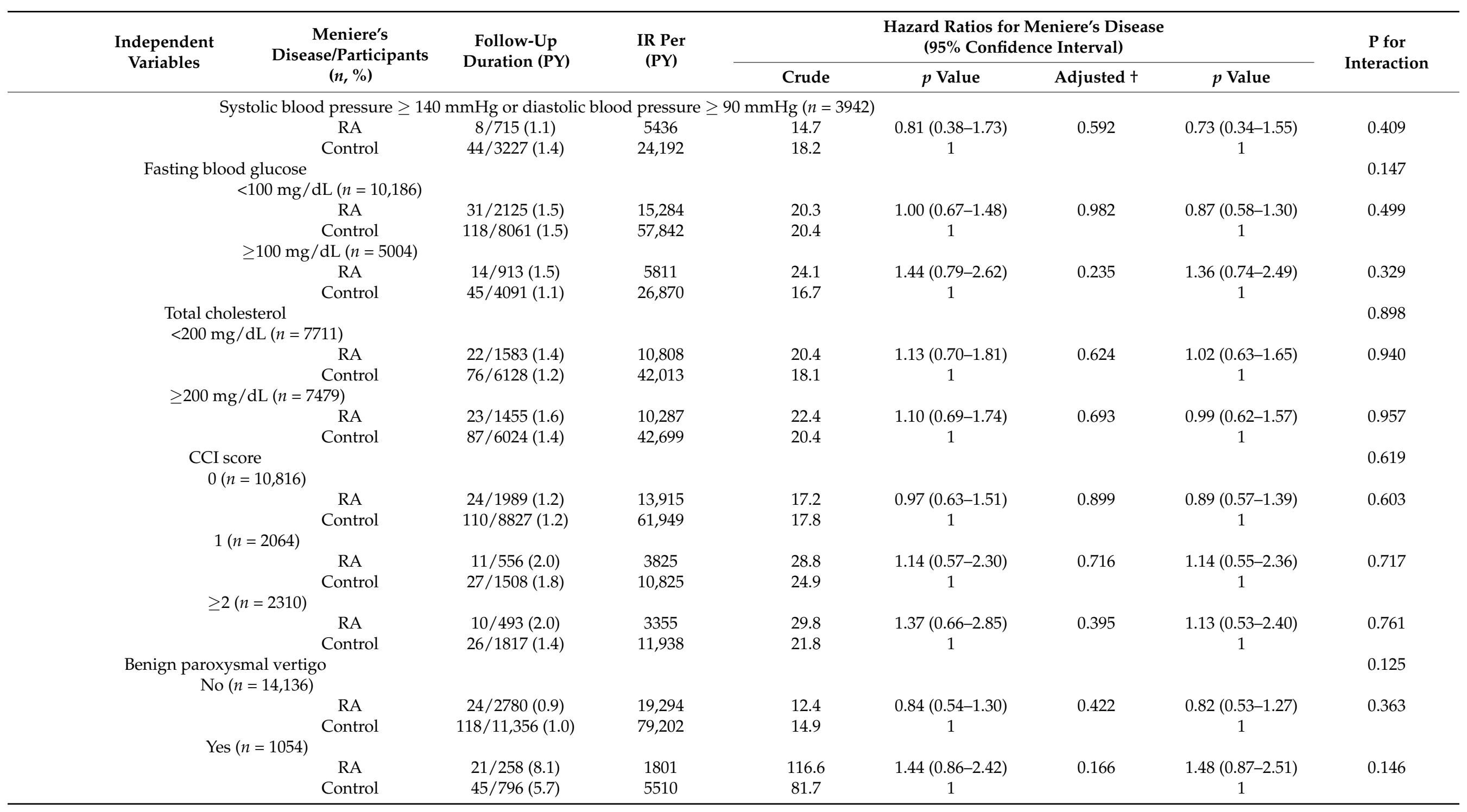


Table 3. Cont.

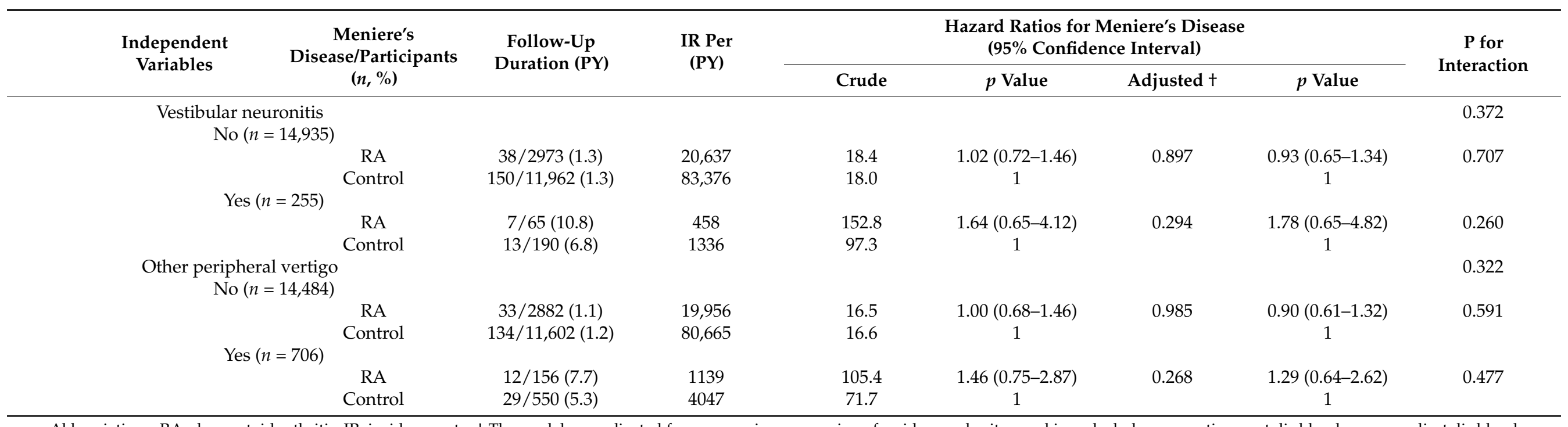

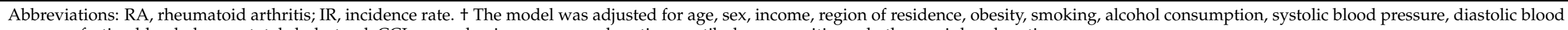
pressure, fasting blood glucose, total cholesterol, CCI scores, benign paroxysmal vertigo, vestibular neuronitis, and other peripheral vertigo. 
The analysis of the subgroups of participants $<60$ years old, men, women, participants with low income, participants with high income, urban residents, and rural residents did not show a significant association of RA with MD in either the crude model or the adjusted model (all $p>0.05$ and $\mathrm{P}$ for interaction $>0.05$, Table 3 ). The analysis of additional subgroups of patients with the comorbidities of obesity, smoking, alcohol consumption, blood pressure, fasting blood glucose, total cholesterol, CCI score, benign paroxysmal vertigo, vestibular neuronitis, and other peripheral vertigo did not demonstrate a significant association of RA with MD in either the crude model or the adjusted model (all $p>0.05$ and $P$ for interaction $>0.05$ ).

\section{Discussion}

We could not determine whether pre-existing RA may increase the risk of MD in the adult population. Although the older population ( $>60$ years old) showed a higher risk of MD associated with RA in the crude analysis, the association of prior RA with MD was not evident after adjusting for other possible confounders. This study improved previous findings on the potential association of RA with MD by using a large population cohort and considering many confounders, including past medical histories, lifestyle factors, and other vestibular disorders. Moreover, comprehensive subgroup analyses were conducted and identified no significant differential contribution of demographic factors, comorbidities, or other vestibular disorders to the relation of RA with MD.

The association of RA with MD has been controversial. Several previous studies suggested the association of RA with MD $[13,22,23]$. In a systematic review, the average point prevalence of RA was estimated to be approximately $4.7 \%$ (range $=1.0-10.0 \%$ ) in patients with MD [13], which was higher than the prevalence of MD in the general population $(0-1.1 \%)$ [13]. In addition, the symptomatic progression of hearing loss and vertigo in MD were correlated with increased levels of lymphocytes in systemic autoimmune diseases $\left(\mathrm{R}^{2}=0.52, p=0.01\right.$ for hearing loss with CD19 cells and $\mathrm{R}^{2}=0.12, p=0.05$ for hearing loss CD8 cells) [22]. Among 41 patients with MD, 20\% of patients showed autoimmunity to type II collagen, and these patients demonstrated a higher rate of the specific HLA-DRB1 genotype of HLA-DRB1*0405 than other patients (63\% vs. 12\%) [23]. This HLA-DRB1*0405 genotype is a susceptible genotype for RA, which implies shared genetic susceptibility to both MD and RA [23]. However, most previous studies lacked a control population and had a small study population. In addition, these previous studies might not have appropriately adjusted for confounders. In a large population study with a control population, the potential association of RA with MD was not strong enough to show statistical significance, as shown in the present results.

There was no significant association between RA and MD in the present study. Because comorbidities, including other vestibular disorders and lifestyle factors, were adjusted for in the present study, the mediating effects of these factors may have been alleviated in this study. Conversely, the confounders that were not adjusted for may have mediated the links between RA and MD in previous studies. In the older age subgroup, a previous history of RA was positively related to MD before adjusting for other variables in the present study. The high prevalence of comorbidities in the older population could impose additional associations between RA and MD before adjusting for these confounding factors. Moreover, the modulation of autoimmunity by medications for RA, including DMARDs, could have attenuated the impact of RA on the new onset of MD in the present study. A case report demonstrated that a patient with RA suffered from vestibular vertigo symptoms, which was attributed to immunosuppression by anti-rheumatic medication with a DMARD [24]. In addition, patients with RA can be treated with glucocorticoids as an adjunct treatment to conventional DMARDs. Because systemic glucocorticoids are also used in refractory MD, this could be another possible confounder in this study. Medication histories and measures of disease activities were not available in the present study. Future studies with information on the management of RA will be warranted to unravel the impact of RA management on the occurrence of MD. 
The association of RA with MD may be limited to certain types of MD, such as autoimmune-mediated MD. Although autoimmunity is one of the pathophysiologic factors associated with the occurrence of MD [10], other pathophysiologic factors have been proposed to underlie the occurrence of MD, such as inflammation, viral infection [25], allergy [26], and genetic factors [11,27]. For instance, a retrospective study reported a higher prevalence of RA and autoimmune disease in patients with familial MD than in patients with sporadic MD $(16.9 \%$ vs. $4.5 \%, p=0.002)$ [28]. The proportion of individuals with familial MD was estimated to be only approximately $2.6-23.5 \%$ of patients with MD [28]. In addition, other vestibular disorders or central diseases causing vertigo could contribute to vertigo in patients with RA, which could be confused with MD. A prospective study found that among 81 RA patients, 21 patients $(24.69 \%)$ showed central vertigo, five patients $(6.17 \%)$ showed peripheral vertigo, and six patients $(7.4 \%)$ showed mixedtype vertigo in videonystagmography tests [29]. A few case reports described vertebral artery insufficiency or occlusion causing recurrent vertigo in patients with RA [30,31]. Because the present cohort included participants with all types of MD, the impact of RA on MD might not be considerable.

This study included 3038 RA patients, which is one of the largest cohort studies on RA. Data on many covariates, including demographic factors, lifestyle factors, chronic diseases, and other vestibular disorders, were collected, and these covariates were adjusted for to minimize possible confounding effects. However, the number of patients with MD was not sufficient $(n=208)$, which could have contributed to the nonsignificant association of RA with MD found in the present study. In addition, the severities and durations of RA and MD were heterogeneous in our cohort. Because this study used health claim data, the laboratory findings of autoimmune antibodies and the results of vestibular function tests were not available. Although this study excluded the patients with other vestibular disorders, otologic diseases which could be an etiology of MD, such as acoustic trauma and otitis media, were not excluded. However, both RA and MD were diagnosed by clinical physicians, and participants had treatment histories for their diseases; individuals with subclinical or mild cases were excluded in this study. Although numerous variables were adjusted for, other confounders that were not analyzed in this study, such as stress, nutritional status, and physical activity, may have had an effect on the results.

\section{Conclusions}

A prior history of RA was not associated with an increased risk of MD in the adult population. Although the higher risk of MD related with RA was demonstrated in old age population in univariate analysis, the association of RA with MD was not valid after considering other comorbidities, including other vestibular disorders.

Author Contributions: H.G.C. designed the study; D.M.Y. and H.G.C. analyzed the data; S.Y.K., J.H.K., M.J.K., J.-H.K., and H.G.C. drafted and revised the paper; H.G.C. drew the figures. All authors have read and agreed to the published version of the manuscript.

Funding: This work was supported in part by research grants (NRF-2018-R1D1A1A02085328, 2020R1A2C4002594, and 2021-R1C1C1004986) from the National Research Foundation (NRF) of Korea. The APC was funded by NRF-2021-R1C1C1004986.

Institutional Review Board Statement: The ethics committee of Hallym University (2020-07-22) permitted this study following the guidelines and regulations.

Informed Consent Statement: Written informed consent was waived by the Institutional Review Board.

Data Availability Statement: Releasing of the data by the researcher is not legally permitted. All data are available from the database of the Korea Center for Disease Control and Prevention. The Korea Center for Disease Control and Prevention allows data access, at a particular cost, for any researcher who promises to follow the research ethics. The data of this article can be downloaded from the website after agreeing to follow the research ethics.

Conflicts of Interest: The authors declare no conflict of interest. 


\section{References}

1. Scott, D.L.; Wolfe, F.; Huizinga, T.W. Rheumatoid arthritis. Lancet 2010, 376, 1094-1108. [CrossRef]

2. Minichiello, E.; Semerano, L.; Boissier, M.C. Time trends in the incidence, prevalence, and severity of rheumatoid arthritis: A systematic literature review. Joint Bone Spine 2016, 83, 625-630. [CrossRef]

3. McInnes, I.B.; Schett, G. The pathogenesis of rheumatoid arthritis. N. Engl. J. Med. 2011, 365, 2205-2219. [CrossRef]

4. Bullock, J.; Rizvi, S.A.; Saleh, A.M.; Ahmed, S.S.; Do, D.P.; Ansari, R.A.; Ahmed, J. Rheumatoid Arthritis: A Brief Overview of the Treatment. Med. Princ Pract. 2018, 27, 501-507. [CrossRef] [PubMed]

5. Conforti, A.; Di Cola, I.; Pavlych, V.; Ruscitti, P.; Berardicurti, O.; Ursini, F.; Giacomelli, R.; Cipriani, P. Beyond the joints, the extra-articular manifestations in rheumatoid arthritis. Autoimmun. Rev. 2021, 20, 102735. [CrossRef] [PubMed]

6. Gaino, J.Z.; Bértolo, M.B.; Nunes, C.S.; de Morais Barbosa, C.; Sachetto, Z.; Davitt, M.; de Paiva Magalhães, E. Disease-related outcomes influence prevalence of falls in people with rheumatoid arthritis. Ann. Phys. Rehabil. Med. 2019, 62, 84-91. [CrossRef]

7. Ihler, F.; Stoycheva, I.; Spiegel, J.L.; Polterauer, D.; Müller, J.; Strobl, R.; Grill, E. Diagnosis of Meniere's disease according to the criteria of 2015: Characteristics and challenges in 96 patients. J. Vestib. Res. 2021, 1-13. [CrossRef]

8. Yang, T.H.; Xirasagar, S.; Cheng, Y.F.; Wu, C.S.; Kuo, N.W.; Lin, H.C. Peripheral Vestibular Disorders: Nationwide Evidence From Taiwan. Laryngoscope 2021, 131, 639-643. [CrossRef] [PubMed]

9. Kotimaki, J. Meniere's disease in Finland. An epidemiological and clinical study on occurrence, clinical picture and policy. Int, J. Circumpolar Health 2003, 62, 449-450. [CrossRef]

10. Greco, A.; Gallo, A.; Fusconi, M.; Marinelli, C.; Macri, G.F.; de Vincentiis, M. Meniere's disease might be an autoimmune condition? Autoimmun. Rev. 2012, 11, 731-738. [CrossRef] [PubMed]

11. Hegemann, S.C.A. Meniere's disease caused by CGRP-A new hypothesis explaining etiology and pathophysiology. Redirecting Meniere's syndrome to Meniere's disease. J. Vestib. Res. 2020, 31, 311-314. [CrossRef]

12. Lee, D.H.; Han, J.; Jang, M.J.; Suh, M.W.; Lee, J.H.; Oh, S.H.; Park, M.K. Association between Meniere's disease and air pollution in South Korea. Sci. Rep. 2021, 11, 13128. [CrossRef]

13. Caulley, L.; Quimby, A.; Karsh, J.; Ahrari, A.; Tse, D.; Kontorinis, G. Autoimmune arthritis in Meniere's disease: A systematic review of the literature. Semin. Arthritis Rheum. 2018, 48, 141-147. [CrossRef] [PubMed]

14. Derebery, M.J.; Rao, V.S.; Siglock, T.J.; Linthicum, F.H.; Nelson, R.A. Meniere's disease: An immune complex-mediated illness? Laryngoscope 1991, 101, 225-229. [CrossRef] [PubMed]

15. Phillips, J.S.; Westerberg, B. Intratympanic steroids for Meniere's disease or syndrome. Cochrane Database Syst. Rev. 2011, CD008514. [CrossRef]

16. Kim, S.Y.; Min, C.; Oh, D.J.; Choi, H.G. Tobacco Smoking and Alcohol Consumption Are Related to Benign Parotid Tumor: A Nested Case-Control Study Using a National Health Screening Cohort. Clin. Exp. Otorhinolaryngol. 2019, 12, 412-419. [CrossRef] [PubMed]

17. Kim, S.Y.; Min, C.; Park, B.; Choi, H.G. Bidirectional association between GERD and rheumatoid arthritis: Two longitudinal follow-up studies using a national sample cohort. Clin. Rheumatol. 2021, 40, 1249-1257. [CrossRef]

18. Kim, S.Y.; Song, Y.S.; Wee, J.H.; Min, C.; Yoo, D.M.; Choi, H.G. Association between Meniere's disease and thyroid diseases: A nested case-control study. Sci. Rep. 2020, 10, 18224. [CrossRef]

19. Kim, S.Y.; Min, C.; Yoo, D.M.; Chang, J.; Lee, H.-J.; Park, B.; Choi, H.G. Hearing impairment increases economic inequality. Clin. Exp. Otorhinolaryngol. 2021, 14, 278-286. [CrossRef] [PubMed]

20. World Health Organization, International Association for the Study of Obesity, International Obesity Task Force. The Asia-Pacific Perespective: Redefining Obesity and its Treatment; Health Communications Australia Pty Ltd.: Sydney, Australia, 2000.

21. Kim, J.-H.; Wee, J.-H.; Choi, H.-G.; Park, J.-Y.; Hwang, Y.I.; Jang, S.H.; Jung, K.-S. Association Between Statin Medication and Asthma/Asthma Exacerbation in a National Health Screening Cohort. J. Allergy Clin. Immunol. Pract. 2021, 9, $2783-2791$. [CrossRef]

22. Gazquez, I.; Soto-Varela, A.; Aran, I.; Santos, S.; Batuecas, A.; Trinidad, G.; Perez-Garrigues, H.; Gonzalez-Oller, C.; Acosta, L.; Lopez-Escamez, J.A. High prevalence of systemic autoimmune diseases in patients with Meniere's disease. PLoS ONE 2011, 6, e26759. [CrossRef]

23. Koo, J.-W.; Oh, S.H.; Chang, S.O.; Park, M.H.; Lim, M.J.; Yoo, T.-J.; Kim, C.S. Association of HLA-DR and type II collagen autoimmunity with Meniere's disease. Tissue Antigens 2003, 61, 99-103. [CrossRef]

24. Roberts, R.A. Management of Recurrent Vestibular Neuritis in a Patient Treated for Rheumatoid Arthritis. Am. J. Audiol. 2018, 27, 19-24. [CrossRef]

25. Arenberg, I.K.; Lemke, C.; Shambaugh, G.E., Jr. Viral theory for Meniere's disease and endolymphatic hydrops: Overview and new therapeutic options for viral labyrinthitis. Ann. N. Y. Acad. Sci. 1997, 830, 306-313. [CrossRef] [PubMed]

26. Derebery, M.J.; Berliner, K.I. Prevalence of allergy in Meniere's disease. Otolaryngol. Head Neck Surg. 2000, 123, 69-75. [CrossRef] [PubMed]

27. Oh, E.H.; Shin, J.-H.; Kim, H.-S.; Cho, J.W.; Choi, S.Y.; Choi, K.-D.; Rhee, J.-K.; Lee, S.; Lee, C.; Choi, J.-H. Rare Variants of Putative Candidate Genes Associated With Sporadic Meniere's Disease in East Asian Population. Front. Neurol. 2019, 10, 1424. [CrossRef]

28. Hietikko, E.; Sorri, M.; Mannikko, M.; Kotimaki, J. Higher prevalence of autoimmune diseases and longer spells of vertigo in patients affected with familial Meniere's disease: A clinical comparison of familial and sporadic Meniere's disease. Am. J. Audiol. 2014, 23, 232-237. [CrossRef] 
29. Ozkiris, M.; Kapusuz, Z.; Gunaydin, I.; Kubilay, U.; Pirti, I.; Saydam, L. Does rheumatoid arthritis have an effect on audiovestibular tests? Eur. Arch. Otorhinolaryngol. 2014, 271, 1383-1387. [CrossRef]

30. Loeb, M.; Bookman, A.; Mikulis, D. Rheumatoid arthritis and vertebral artery occlusion: A case report with angiographic and magnetic resonance demonstration. J. Rheumatol. 1993, 20, 1402-1405. [PubMed]

31. Fujiwara, H.; Kaito, T.; Makino, T.; Yonenobu, K. Positional occlusion of the vertebral artery in a case of rheumatoid atlantoaxial subluxation presenting with multiple cerebral and cerebellar infarction. Mod. Rheumatol. 2012, 22, 605-609. [CrossRef] 